\title{
Happiness: A Novel Outcome Measure in Stroke?
}

\author{
Tissa Wijeratne (D) ${ }^{1-4}$ \\ Carmela Sales ${ }^{1,2}$ \\ Chanith Wijeratne ${ }^{5}$ \\ Mihajlo Jakovljevic (D) 6,7 \\ 'Department of Neurology, Sunshine \\ Hospital, Western Health, St. Albans, \\ VIC, Australia; ${ }^{2}$ Department of \\ Psychology \& Counselling, School of \\ Psychology \& Public Health, La Trobe \\ University, Bundoora, VIC, Australia; \\ ${ }^{3}$ Department of Medicine, AIMSS, \\ Melbourne Medical School, University of \\ Melbourne, Sunshine Hospital, St Albans, \\ VIC, Australia; ${ }^{4}$ Department of Medicine, \\ University of Rajarata, Salypura, \\ Anuradhapuraya, Sri Lanka; ${ }^{5}$ Monash \\ Medical School, Monash University, \\ Clayton, VIC, Australia; ${ }^{6}$ Department \\ Global Health Economics \& Policy, \\ University of Kragujevac Faculty of \\ Medical Sciences, Kragujevac, Serbia; \\ ${ }^{7}$ Institute of Comparative Economic \\ Studies, Hosei University Faculty of \\ Economics, Tokyo, Japan
}

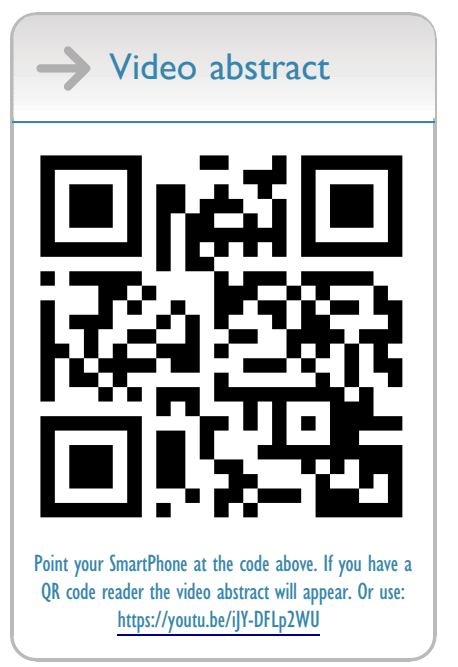

Correspondence: Tissa Wijeratne Email Tissa.wijeratne@wh.org.au

\begin{abstract}
In this narrated review, we draw attention to the use of happiness as a novel outcome measure in clinical research studies regarding patients with stroke. Commonly used outcome measures in clinical trials in stroke rehabilitation include the modified Rankin Score (mRS), Functional Impairment Measures (FIM), Barthel Index and quality of life (QoL). Despite being a part of QoL, happiness is arguably a significant construct on its own. While QoL assesses perceptions of various extrinsic aspects of life, happiness may be used as a measure of subjective enjoyment of life after an illness. We review the literature discussing the use of happiness as a formal outcome measure in stroke care and subacute and long-term stroke rehabilitation. Ultimately we recommend the wider use of happiness as an outcome measure where appropriate in these settings.
\end{abstract}

Keywords: stroke, quality of life, happiness, brain health

\section{Introduction}

Happiness is a concept first defined more than 2000 years ago as a state of being and doing well. ${ }^{1}$ Over the past century, there has been significant expansion on the definition of happiness. Social scientists highlight the importance of human relationships to attain happiness and be satisfied with life. A religious perspective underscores spirituality as enhancing people's virtuosity, which is suggested to be a key component of happiness. ${ }^{2,3}$ A unique school of thought that redefines happiness emerged after World War II. A happy life is described using this outlook as a life that is good, pleasant, and meaningful. Martin Seligman refers to this as positive psychology. ${ }^{4}$ Positive psychology suggests that happiness can be attained by focusing on positive emotions and capitalizing on individual strengths to cope with mental illnesses and other ailments. ${ }^{5}$

\section{Happiness, Positive Psychology and Social Well-Being}

The definition of happiness is complex and variable. Positive psychology attempts to define happiness using "scientifically informed perspectives on what makes life worth living", focusing on "aspects of the human condition that lead to happiness, fulfilment, and flourishing". 6

It focuses on every individuals positive subjective experiences in the past, present and future, also accounting for the virtues of each individual that make them a contributor to societal productivity. ${ }^{7}$ Core to the concepts of positive psychology is the idea of subjective well-being. In 2011, the PERMA theory was conceived. This theory suggests there is a correlation between various variables (positive emotion, engagement, relationships, meaning and accomplishment) and the 
subjective concept of well-being. ${ }^{8}$ Steptoe likewise equates happiness to subjective well-being. This idea of well-being includes

affective well-being (feelings of joy and pleasure), eudaimonic well-being (a sense of meaning and purpose in life) and evaluative well-being. (overall life satisfaction). ${ }^{9}$

Empirical corroboration from behavioral research supports this idea, providing substantial evidence that achieving the aforementioned improves productivity in terms of health, relationships, work, and creativity. ${ }^{8,10,11}$ Although quality of life (QoL) and happiness are often used interchangeably, various literatures propose that this is incorrect. ${ }^{13,14}$ Veenhoven implies that happiness is a mere subset of QOL since QoL more broadly describes quality of one's living environment, their performance, and their subjective enjoyment of life. ${ }^{14}$

\section{Scales to Measure Happiness and Subjective Well-Being}

Dissatisfaction with the practice of orthodox medicine has led to increasing interest in the philosophies of holistic medicine. Holistic medicine seeks to avoid focusing solely on the physical aspect of disease management. Instead, emotional, spiritual, and social factors are also reflected upon. ${ }^{15,16}$ The increased popularity of this approach highlights the importance of finding parameters that can measure a patient's quality of life, sense of well-being and degree of happiness. ${ }^{17}$ In 2011 international interest into finding such a parameter was sparked when the United Nations General Assembly encouraged nations to measure their happiness for use in the World Happiness Report. International interest was sparked into finding such a parameter in 2011 as the United Nations General Assembly encouraged nations to measure their level of happiness for use in the World Happiness Report. ${ }^{18}$ Before the advent of positive psychology, happiness was gauged in clinical research by the five-item Satisfaction With Life Scale. ${ }^{12}$ Conceptualized in 1985 , it is a validated metric that aims to assess subjective well-being by using the affective and cognitive aspects of life satisfaction. ${ }^{12}$ A few years later Watson et al formulated the Positive and Negative Affect Schedule (PANAS), a 20-item questionnaire which not only gauges an individual's high energy states of enjoyment but also investigates states of distress and undesirable engagements. ${ }^{19}$ The Oxford Happiness Inventory uses instead a 29-question questionnaire based on Argylle's three-pronged definition of happiness. This definition claims that life satisfaction involves the presence of positive factors, the absence of negative factors and the existence of satisfaction. ${ }^{20}$ This questionnaire has been translated to several languages. It was the basis from which the Oxford Happiness Questionnaire and Oxford Happiness measure were constructed in 2002 and 2010 respectively. $^{21,22}$

The establishment of positive psychology in 1997 was immediately followed by a great deal of related research. In 2005, the Orientation to Happiness Index was established. This psychometric scale sought to measure life satisfaction based on pleasure, engagement and meaning. ${ }^{23}$ Five years later, Tennant et al proposed the Warwick Edinburgh Mental Well-Being Scale, a 14-item test that looks into the hedonic and eudaimonic aspects of mental health. Like other metrics it covers positive affect, functioning and interpersonal relationships. ${ }^{24}$ In 2010, Pavot and colleagues introduced the Temporal Satisfaction With Life Scale (TSWLS), which has been shown to positively correlate with global life satisfaction. ${ }^{25}$ It notably incorporates past, present and future facets of an individual's definition of satisfaction. $^{25}$ Several modifications of existing wellbeing scales have also been made over the past ten years, yielding many further scales and indices. The BBC Subjective Well-Being Scale (BBC-SWB) was created by experts from the United Kingdom. This measures an individual's relationship status along with their psychological and physical well-being via a comprehensive 24-item test. ${ }^{26}$ Two years later researchers from Australia developed the Personal Well-Being Index, integrating known predictors of life satisfaction and subjective well-being while also including other elements such as standard of living, health, future security, and religion. ${ }^{27}$

\section{Happiness as an Outcome in Clinical Research}

Happiness has rarely been explored as an outcome in clinical research due to its inherent subjectivity. However, a convincing amount of data suggests that an individual's experience of happiness, subjective well-being and positive psychology are associated with physiological changes which may have a systemic effect. ${ }^{28,29}$ The Heart and Soul study involving more than 1000 patients suggested that positive affect directly correlated with increased chance of survival among patients with coronary 
heart disease using the Positive and Negative Affect Schedule. ${ }^{30}$ Among cancer patients, happiness was measured using the Fordyce scale after psycho-intervention and was also shown to correlate with positive outcomes. $^{31}$ The OSAKA study, which employed the Subjective Happiness Scale among patients with dry eyes, demonstrated an inverse relationship between selfreported symptoms of dry eyes and happiness. ${ }^{32}$

The impact of happiness on patients with neurological diseases has also been assessed by various studies using different parameters. Pacchetti et al used the Happiness Measure to evaluate the emotional effects of music therapy among patients with Parkinson's Disease, suggesting that it had notable benefits. ${ }^{33}$ Happiness levels during the treatment of patients with relapsing remitting MS were investigated in a prospective study in Israel. ${ }^{34}$ Using the Oxford Happiness Inventory (OHI) and the Satisfaction with Life Scale (SLS), it was concluded that patients who were treated with interferon-beta-1a were as happy as their healthy counterparts ${ }^{34}$ Similarly, the effect of Emotional Intelligence Training on the happiness levels of patients with epilepsy was studied in a randomized control trial involving 70 patients. The Oxford Happiness Questionnaire was used to demonstrate that there was a significant difference before and after treatment using this intervention. ${ }^{35}$ While objective measures of happiness are deemed extremely useful in clinical research, Szymanski argues that they are not usually tantamount to tangible indicators. ${ }^{36}$ For instance, in a qualitative study among female PD patients they claimed that a sense of connection, harmony and control over one's life were the main indicators for emotional well-being, factors which some measures of happiness do not consider. ${ }^{37}$ The recent expansion of research in this field has highlighted the utility of happiness as an outcome, be it measured qualitatively or quantitatively. However, despite clinical medicine's focus on mental health and well-being promotion, there is still limited data on positive psychology-based interventions and outcomes.

\section{Stroke and Unhappiness}

Stroke is a common condition that significantly impacts physical, emotional, and mental health, often leaving patients with profound disability. Often the emotional burden of the disease cannot be coped with. Patients describe this as a psychological crisis impairing their ability to receive and comprehend. ${ }^{38}$ Viitanen states that the absence of physical disability post-stroke can still leave patients susceptible to decreased global satisfaction due to acopia is perhaps one of the most common conditions that significantly impacts physical, emotional, and mental health. Despite advances in stroke diagnosis and treatment, many patients are still left with profound disability. Given the acuteness of the devastating sequelae of stroke, there is often a mismatch in the emotional burden of the disease and the patient's capacity to cope. Acute stroke patients often describe this phenomenon as a psychological crisis resulting in the impairment of their capacity to receive and comprehend. ${ }^{38}$ Viitanen also concludes that the absence of physical disability post-stroke may still make patients susceptible to decreased global satisfaction due to acopia. ${ }^{39}$ The Lausanne emotion in stroke study in 2015 has shown that $40 \%$ of patients suffering from their first ever stroke was left in a state of sadness, while $18 \%$ were unable to adapt to the changes to their life. Notably $44 \%$ were in a state of denial during the acute period. ${ }^{40}$ The same study also concluded that a history of alcohol use, being female (It is worth noting the fact that acute stroke in women differs from men in the distribution of risk factors and stroke subtype, stroke severity, and outcome as demonstrated by many researchers ${ }^{41}$ or having a haemorrhagic stroke all increased the likelihood of sadness. In another prospective study involving more than 273 patients suffering their first uncomplicated stroke, it was demonstrated that crying and overt sadness in the acute period predicted post-stroke depression in one year's time. ${ }^{42}$ Similar findings were noted in more literature in Sweden which used self-rated scales and concluded that more than $50 \%$ of patients remained sad at the end of three months. Fatigue and an increased risk of depression were predicted by this study for these patients. ${ }^{43}$ If sadness is not averted at the end of one year, life satisfaction tends to remain poor for up to three years. ${ }^{44}$ This emotion likely emanates from discontent regarding vocational situation, sexual life, physical health post stroke and mental health post stroke. ${ }^{45}$ If this is not swiftly overcome it may lead to post-stroke depression that heavily impacts patients' quality of life, as well as likely negatively influencing their chance of survival and rehabilitation. ${ }^{46,47}$

\section{Stroke, Happiness and Positive Affect}

While sadness and negative emotions outweigh happiness and positive psychology in the acute stroke period, there is evidence to suggest that improvement is usually imminent in the subacute period. ${ }^{48}$ Ostir et al describes this as 
a dynamic process that can occur regardless of age, gender and ethnicity. ${ }^{48}$ In a study involving more than 800 patients with acute stroke, there was an improvement in the patients' happiness as measured by respective positive emotions scores by $35 \%$ after three months. ${ }^{48}$ The popularity of social media has also made it possible to assess people's positive emotions by evaluation of their tweets and posts. Using the Plutchik model and hedonometer tool, Rudolph et al concluded that positive emotions such as anticipation, trust and joy were more commonly displayed by female stroke survivors than their male counterparts. ${ }^{49}$ An analysis of more than 800,000 tweets from stroke survivors suggests that females had more favorable outcomes in terms of rankings on the happiness index and global positive emotions. ${ }^{49}$ This gender dependency was similarly observed by Wyller and colleagues as they assessed subjective well-being using variables such as satisfaction, strength, calmness, and cheerfulness. ${ }^{50}$ The same study concluded that older age, well-established social connections, and a sound pre-existing general and mental health could also account for improved positive emotion among stroke survivors. ${ }^{50}$ Data from the Stroke Recovery in Underserved Population database (consisting of more than 900 patients) indicates that among patients undergoing rehabilitation, those who had a higher positive affect at discharge had lower pain ratings after a threemonth follow-up period. ${ }^{51}$ More importantly, these patients also had an advantage in terms of functional, motor, and cognitive recovery. ${ }^{48}$ Further analysis of the same population implies that these patients also displayed greater social participation after discharge. ${ }^{52}$ This likely stems from every individual's inherent desire to engage in strategies and activities that would bring about fast recovery, otherwise known as the hierarchy of sustainable happiness. ${ }^{53}$

Interventions to promote happiness and positive psychology have also been employed in treating patients with stroke. A randomized control trial of more than 50 patients with stroke reported that music therapy (also known as rhythmic auditory stimulation (RAS) therapy) improved their emotional regulation, capacity to concentrate and level of happiness. ${ }^{54}$ This is supported by an additional qualitative study which reported that acute stroke patients who listened to music for at least an hour each day showed an improved mood and were more relaxed. ${ }^{55}$ Another group of investigators from the US provided further evidence for the benefits of music therapy. Their data suggests that music therapy not only benefits a patient's level of happiness but also has a positive effect on their physical mobility and flexibility, as well as improving their interpersonal relationships. ${ }^{56}$

Art sessions are another intervention shown to enhance a stroke patient's emotional well-being. Data from a randomized control trial of stroke survivors in the UK showed that those who participated in art sessions during rehabilitation had more improvement in their PANAS scores post-intervention at 4 and 12 weeks compared to controls. ${ }^{57} \mathrm{~A}$ distinct sense of pleasure and revitalized engagement was also experienced by patients who were involved in Healing Arts, a specialized programme intended for stroke patients. ${ }^{58}$ In the same study these patients also showed improved confidence, feelings of achievement and feelings of empowerment. ${ }^{58}$

Physical leisure therapy involving education and various recreational activities also has a significant impact on stroke patients' holistic recovery. Drummond et al $t$ explored the effects of leisure-integrated rehabilitation among stroke patients, finding that those who were involved in it had higher happiness scores. ${ }^{59}$ Further analysis of this data revealed that patients with higher scores had more improvement in their mobility and psychological wellness. ${ }^{60}$ A subsequent randomized control trial involving $^{61}$ subjects also demonstrated that patients who participated in community-based leisure activities had an advantage over controls in terms of leisure satisfaction, improving their mood and general well-being. ${ }^{61}$

Neurological mechanisms of happiness and stroke

The physiological changes caused by happiness in healthy individuals have been demonstrated well in literature. However, there is no existing clinical data which directly correlates biochemical changes and happiness levels among stroke patients. A study by Steptoe et al concludes that biomarkers such as cortisol and fibrinogen, which are chemical mediators of stress, inversely correlate with happiness. ${ }^{62}$ It is known that patients with post-stroke depression (PSD) have derangement in the hypothalamic pituitary axis, which may contribute to fluctuations in cortisol $^{63}$ Harney et al infers that patients with an abnormal Dexamethasone Suppression Test in the subacute period are more susceptible to PSD in the long term ${ }^{64}$ A similar trend was observed among patients with increased fibrinogen levels in the acute stroke period. Luan et al prospectively investigated the effects of baseline fibrinogen levels in more than 400 acute stroke patients regardless of aetiology and proposed its potential utility as a biomarker for PSD. ${ }^{65}$ 
Inflammatory markers are also known to play an essential role in the physiology of happiness. In a study of 160 happy Japanese individuals, they all displayed inherently lower levels of interferon- $\gamma$ (IFN- $\gamma$ ), which is otherwise elevated in PSD. ${ }^{66}$ Wijeratne and Sales proposed that Post Stroke Depression as the norm rather than the exception in a recent, comprehensive reviews on this key topic. ${ }^{67}$ The possible protective role of happiness in various inflammatory conditions is supported by another study among patients with T2 Diabetes mellitus ${ }^{68}$ IL-6 and monocyte chemoattractant protein-1 (MCP-1) were noted to be at lower levels among individuals who perceived themselves as happy. ${ }^{68}$ Interestingly, when subjected to stress, the same subjects had a modest reaction in terms of the acute rise in their inflammatory markers. ${ }^{68}$ As with cortisol and fibrinogen, the link between inflammatory cytokines in PSD is wellestablished. ${ }^{67-70}$ In the same manner, stroke is itself linked to a chronic inflammatory state and thus is also associated with an increase in levels of inflammatory biomarkers. ${ }^{70}$ This connection is a possible reason why stroke patients are generally unhappy and likely to suffer later depression.

The potential role of neuroplasticity in the experience of happiness among stroke patients is worth noting. This concept was proposed more than 20 years ago, highlighting the capacity of neural circuitry to change in response to various stimuli such as stress or injury. ${ }^{71}$ This could possibly explain why music therapy has improved the level of happiness among post stroke patients. Experimental studies on Sprague-Dawley rats have shown that there are positive effects of musical enrichment on the hippocampal region of depressed rats. ${ }^{72}$ The existence of such a mechanism is also supported by neurophysiological studies showing that patients who were musically trained for at least 3 months had enhanced evoked responses, suggesting possible neuroplastic changes. ${ }^{73}$ By virtue of long-term potentiation, music has also been shown to activate cerebral pleasure centers such as the nucleus accumbens and the ventral tegmental area, as well as activating emotional processing regions of the brain. ${ }^{74}$ This may further apply to visual art-induced neuroplasticity, as evidenced by the magnification of visual evoked responses among art-exposed stroke patients. ${ }^{77}$

Apart from these neurobiological associations, physical activity among post-stroke patients also impacts significantly on their emotional well-being ${ }^{48,51-53}$ This is parallel to observations made in a study among patients with cerebral palsy, in which happiness correlated with physical activity $^{77}$ It is also well-established that patients engaged in leisure-related exercises have maintained their short and long term perception of happiness, ${ }^{76,77}$ Moreover, functional studies have shown that activities such as running promote a connection between the amygdala, orbitofrontal cortex and insula. This clinically manifests as a happy state with a concomitant uncoupling and inhibition of fear-related structures such as the parahippocampus and subgenual cingulate $^{78}$ Pain is also alleviated by physical therapy, so reduction of pain may contribute significantly to the improved positive psychology experienced by patients. ${ }^{50}$ Current stroke care pathways do not take into consideration of happiness as an outcome measure. Hachinski and colleagues proposed a definition of brain health in adults as a state of complete physical, mental, and social wellbeing through the continuous development and exercise of the brain. ${ }^{79}$ Cognitive impairment is expected to impact on brain health in this context. The proportion of cognitive impairment due to small vessel disease range from $36-67 \%{ }^{80}$ It is highly possible that the differences between the groups with and without cognitive impairment is related the differences between happiness in these groups while further research is needed to confirm this suggestion.

Ultimately happiness and subjective well-being among stroke patients is likely a function of various biochemical changes linked to the process of neuroplasticity.

\section{Conclusion}

Happiness is a basic human emotion which has been defined, interpreted, and measured in a variety of ways over the course of time. This emotion is remarkably compromised in stroke due to patients' incapacity to cope with sudden sequelae. Multisensory modalities such as physical activity, music and visual art promote emotional recovery by inducing biochemical changes and activating neuroplasticity in pleasurerelated structures of the brain. The promotion of positive psychology-based interventions in the rehabilitation of stroke patients translates to improvement in their physical and subjective well-being, improving their overall quality of life.

\section{Disclosures}

The authors reported no conflicts of interest for this work.

\section{References}

1. Encyclopedia Britannica. Eudaimonia | definition \& Facts. [online]; 2020. Available from: https://www.britannica.com/topic/eudaimonia. Accessed July 17, 2020.

2. Helliwell J, Aknin L. Expanding the social science of happiness. Nature Human Behav. 2018;2(4):248-252. doi:10.1038/s41562-018-0308-5 
3. Rizvi M, Hossain M. Relationship Between Religious Belief and Happiness: a Systematic Literature Review. J Relig Health. 2016;56 (5):1561-1582. doi:10.1007/s10943-016-0332-6

4. Katyal S. Diagnosing Happiness: lessons From Positive Psychology. J Am College Radiol. 2018;15(7):1040-1044. doi:10.1016/j.jacr.2018.03.028

5. Norrish J, Vella-Brodrick D. Positive psychology and adolescents: where are we now? Where to from here? Aust Psychol. 2009;44 (4):270-278. doi:10.1080/00050060902914103

6. Alex Linley P, Joseph S, Harrington S, Wood A. Positive psychology: past, present, and (possible) future. J Posit Psychol. 2006;1(1):3-16. doi:10.1080/17439760500372796

7. Seligman M, Csikszentmihalyi M. Positive psychology: an introduction. Am Psychol. 2000;55(1):5-14. doi:10.1037/0003066X.55.1.5

8. Seligman M. PERMA and the building blocks of well-being. $J$ Posit Psychol. 2018;13(4):333-335. doi:10.1080/17439760.2018.1437466

9. Steptoe A. Happiness and Health. Annu Rev Public Health. 2019;40 (1):339-359. doi:10.1146/annurev-publhealth-040218-044150

10. Diener E, Oishi S, Tay L. Advances in subjective well-being research. Nature Human Behav. 2018;2(4):253-260. doi:10.1038/ s41562-018-0307-6

11. Park C. Integrating positive psychology into health-related quality of life research. Qual Life Res. 2014;24(7):1645-1651. doi:10.1007/ s11136-014-0889-z

12. Diener E, Emmons R, Larsen R, Griffin S. The Satisfaction With Life Scale. J Pers Assess. 1985;49(1):71-75.

13. Susniene D, Jurkauskas A. The Concepts of Quality of Life and Happiness - Correlation and Differences. Eng Econ. 2009;63.

14. DeGirolamo G, editors. Salute e qualità dell vida', Centro Scientifico Editore. Torino, Italia; 2001: 67-95.

15. Berliner H, Salmon J. The Holistic Alternative to Scientific Medicine: history and Analysis. Int $J$ Health Serv. 1980;10 (1):133-147. doi:10.2190/XWR6-5QPX-GEGE-5GWR

16. Borins M. Holistic medicine in family practice. Can Fam Physician. 1984;30:101-106.

17. [No authors listed]. The World Health Organization quality of life assessment (WHOQOL): position paper from the World Health Organization. Social Science \& Medicine.1995;41(10):1403-1409.

18. Helliwell J, Layard R, Sachs J. World Happiness Report 2018. New York: Sustainable Development Solutions Network; 2018.

19. Watson D, Clark L, Tellegen A. Development and validation of brief measures of positive and negative affect: the PANAS scales. J Pers Soc Psychol. 1988;54(6):1063-1070. doi:10.1037/0022-3514.54.6.1063

20. Argyle M, Martin M, Crossland J. Happiness as a function of personality and social encounters. In: Forgas JP, J. M, editors. Innes Recent Advances in Social Psychology: An International Perspective. 1989:189-203.

21. Hills P, Argyle M. The Oxford Happiness Questionnaire: a compact scale for the measurement of psychological well-being. Pers Individ Dif. 2002;33:1073-1082. doi:10.1016/S0191-8869(01)00213-6

22. Robbins M, Francis L, Edwards B. Happiness as Stable Extraversion: internal Consistency Reliability and Construct Validity of the Oxford Happiness Questionnaire Among Undergraduate Students. Current Psychol. 2010;29(2):89-94. doi:10.1007/s12144-010-9076-8

23. Peterson C, Park N, Seligman M. Orientations to happiness and life satisfaction: the full life versus the empty life. J Happiness Stud. 2005;6(1):25-41. doi:10.1007/s10902-004-1278-z

24. Tennant R, Hiller L, Fishwick R, et al. The Warwick-Edinburgh Mental Well-being Scale (WEMWBS): development and UK validation. Health Qual Life Outcomes. 2007;5(1):63. doi:10.1186/ 1477-7525-5-63

25. Pavot W, Diener E, Suh E. The Temporal Satisfaction With Life Scale. $J$ Pers Assess. 1998;70(2):340-354. doi:10.1207/ s15327752jpa7002_11
26. Pontin E, Schwannauer M, Tai S, Kinderman P. A UK validation of a general measure of subjective well-being: the modified BBC subjective well-being scale (BBC-SWB). Health Qual Life Outcomes. 2013;11(1):150. doi:10.1186/1477-7525-11-150

27. McIntyre E, Saliba A, McKenzie K. Subjective wellbeing in the Indian general population: a validation study of the Personal Wellbeing Index. Qual Life Res. 2019;29(4):1073-1081. doi:10.1007/s11136-019-02375-7

28. Dfarhud D, Malmir M, Khanahmadi M. Happiness \& Health: the Biological Factors- Systematic Review Article. Iran J Public Health. 2014;43(11):1468-1477.

29. Sin N. The Protective Role of Positive Well-Being in Cardiovascular Disease: review of Current Evidence, Mechanisms, and Clinical Implications. Curr Cardiol Rep. 2016;18:11. doi:10.1007/s11886-0160792-z

30. Hoen P, Denollet J, de Jonge P, Whooley M. Positive Affect and Survival in Patients With Stable Coronary Heart Disease. J Clin Psychiatry. 2013;74(07):716-722. doi:10.4088/JCP.12m08022

31. Espinoza M, Baños RM, García-Palacios A, et al. Promotion of emotional wellbeing in oncology inpatients using VR. Stud Health Technol Inform. 2012;181:53-57.

32. Kawashima M, Uchino M, Yokoi N, et al. Associations between Subjective Happiness and Dry Eye Disease: a New Perspective from the Osaka Study. PLoS One. 2015;10(4):e0123299. doi:10.1371/journal.pone.0123299

33. Pacchetti C, Mancini F, Aglieri R, Fundarò C, Martignoni E, Nappi G. Active Music Therapy in Parkinson's Disease: an Integrative Method for Motor and Emotional Rehabilitation. Psychosom Med. 2000;62 (3):386-393. doi:10.1097/00006842-200005000-00012

34. Barak Y, Achiron A. Happiness and Personal Growth are Attainable in Interferon-Beta-1a Treated Multiple Sclerosis Patients. J Happiness Stud. 2010;12(5):887-895. doi:10.1007/s10902-010-9234-6

35. Hajisabbagh N, Fereidooni-Moghadam M, Masoudi R, Etemadifar M. The effect of an emotional intelligence component program on happiness in patients with epilepsy. Epilepsy Behav. 2020;106:106972. doi:10.1016/j.yebeh.2020.106972

36. Szymanski L. Happiness As a Treatment Goal. Am J Mental Retardation. 2000;105(5):352. doi:10.1352/0895-8017(2000) $105<0352:$ HAATG $>2.0 . \mathrm{CO} ; 2$

37. Olsson M, Nilsson C. Meanings of feeling well among women with Parkinson's disease. Int J Qual Stud Health Well-Being. 2015;10 (1):28730. doi:10.3402/qhw.v10.28730

38. Backe M, Larsson K, Fridlund B. Patients' conceptions of their life situation within the first week after a stroke event: a qualitative analysis. Intensive Critical Care Nursing. 1996;12(5):285-294. doi:10.1016/S0964-3397(96)80765-8

39. Viitanen M, Fugl-Meyer KS, Bernspång B, Fugl-Meyer AR. Life satisfaction in long-term survivors after stroke. Scand $J$ Rehabil Med. 1988;20(1):17-24.

40. Aybek S, Carota A, Ghika-Schmid F, et al. Emotional Behavior in Acute Stroke. Cognitive Behav Neurol. 2005;18(1):37-44. doi:10.1097/01.wnn.0000152226.13001.8a

41. Arboix $\mathrm{A}$, Cartanyà $\mathrm{A}$, Lowak $\mathrm{M}$, et al. Gender differences and woman-specific trends in acute stroke: results from a hospital-based registry (1986-2009). Clin Neurol Neurosurg. 2014;127:19-24. doi:10.1016/j.clineuro.2014.09.024

42. Carota A, Berney A, Aybek S, et al. A prospective study of predictors of poststroke depression. Neurology. 2005;64(3):428-433. doi:10.1212/01.WNL.0000150935.05940.2D

43. Skånér Y, Nilsson G, Sundquist K, Hassler E, Krakau I. Self-rated health, symptoms of depression and general symptoms at 3 and 12 months after a first-ever stroke: a municipality-based study in Sweden. BMC Fam Pract. 2007;8(1). doi:10.1186/1471-2296-8-61 
44. Aström M, Asplund K, Aström T. Psychosocial function and life satisfaction after stroke. Stroke. 1992;23(4):527-531. doi:10.1161/ 01.STR.23.4.527

45. Langhammer B, Sunnerhagen K, Stanghelle J, Sällström S, Becker F, Fugl-Meyer K. Life satisfaction in persons with severe stroke a longitudinal report from the Sunnaas International Network (SIN) stroke study. Eur Stroke J. 2017;2(2):154-162. doi:10.1177/ 2396987317695140

46. Villa R, Ferrari F, Moretti A. Post-stroke depression: mechanisms and pharmacological treatment. Pharmacol Ther. 2018;184:131-144. doi:10.1016/j.pharmthera.2017.11.005

47. Sivolap Y, Damulin I. Stroke and depression. Zhurnal Nevrologii I Psikhiatrii Im S S Korsakova. 2019;119(9):143. doi:10.17116/ jnevro2019119091143

48. Ostir G, Berges I, Ottenbacher M, Clow A, Ottenbacher K. Associations Between Positive Emotion and Recovery of Functional Status Following Stroke. Psychosom Med. 2008;70(4):404-409.

49. Garcia-Rudolph A, Laxe S, Saurí J, Bernabeu Guitart M. Stroke Survivors on Twitter: sentiment and Topic Analysis From a Gender Perspective. J Med Internet Res. 2019;21(8):e14077.

50. Wyller T, Holmen J, Laake P, Laake K. Correlates of Subjective Well-being in Stroke Patients. Stroke. 1998;29(2):363-367. doi:10.1161/01.STR.29.2.363

51. Berges I, Seale G, Ostir G. Positive affect and pain ratings in persons with stroke. Rehabil Psychol. 2011;56(1):52-57. doi:10.1037/a0022683

52. Berges I, Seale G, Ostir G. The role of positive affect on social participation following stroke. Disabil Rehabil. 2012;34 (25):2119-2123. doi:10.3109/09638288.2012.673684

53. Lyubomirsky S, Sheldon K, Schkade D. Pursuing Happiness: the Architecture of Sustainable Change. Rev General Psychol. 2005;9 (2):111-131. doi:10.1037/1089-2680.9.2.111

54. Baylan S, McGinlay M, MacDonald M, et al. Participants' experiences of music, mindful music, and audiobook listening interventions for people recovering from stroke. Ann N Y Acad Sci. 2018;1423 (1):349-359. doi:10.1111/nyas.13618

55. Forsblom A, Sarkamo T, Laitinen S, Tervaniemi M. The Effect of Music and Audiobook Listening on People Recovering From Stroke: the Patient's Point of View. Music Med. 2010;2(4):229-234. doi:10.1177/1943862110378110

56. Jeong S, Kim MT. Effects of a theory-driven music and movement program for stroke survivors in a community setting. Appl Nursing Res. 2007;20(3):125-131. doi:10.1016/j.apnr.2007.04.005

57. Morris J, Kelly C, Joice S, et al. Art participation for psychosocial wellbeing during stroke rehabilitation: a feasibility randomised controlled trial. Disabil Rehabil. 2017;41(1):9-18. doi:10.1080/ 09638288.2017.1370499

58. Baumann M, Peck S, Collins C, Eades G. The meaning and value of taking part in a person-centred arts programme to hospital-based stroke patients: findings from a qualitative study. Disabil Rehabil. 2012;35(3):244-256. doi:10.3109/09638288.2012.694574

59. Drummond A, Walker M. A randomized controlled trial of leisure rehabilitation after stroke. Clin Rehabil. 1995;9(4):283-290. doi:10.1177/026921559500900402

60. Drummond A, Walker M. Generalisation of the Effects of Leisure Rehabilitation for Stroke Patients. Br J Occup Therapy. 1996;59 (7):330-334. doi:10.1177/030802269605900712

61. Desrosiers J, Noreau L, Rochette A, et al. Effect of a Home Leisure Education Program After Stroke: a Randomized Controlled Trial. Arch Phys Med Rehabil. 2007;88(9):1095-1100. doi:10.1016/j. apmr.2007.06.017

62. Steptoe A, O’Donnell K, Marmot M, Wardle J. Positive affect and psychosocial processes related to health. Br J Psychol. 2008;99 (2):211-227. doi:10.1111/j.2044-8295.2008.tb00474.x
63. Zhang X, Zou W, Yang Y. Effects of IL-6 and cortisol fluctuations in post-stroke depression. J Huazhong Univ Sci Technol. 2016;36 (5):732-735. doi:10.1007/s11596-016-1653-0

64. Harney JH, Fulton C, Ross ED, Rush AJ. Dexamethasone suppression test and onset of poststroke depression in patients with ischemic infarction. J Clin Psychiatry. 1993;54(9):343-348.

65. Luan X, Shen H, Zhao K, Qiu H, Chen H, He J. Plasma Fibrinogen: an Independent Risk Factor for Post- Stroke Depression. Neuropsychiatry. 2017;07:06. doi:10.4172/Neuropsychiatry.1000288

66. Matsunaga M, Isowa T, Yamakawa K, et al. Association between perceived happiness levels and peripheral circulating pro-inflammatory cytokine levels in middle-aged adults in Japan. Neuro Endocrinol Lett. 2011;32(4):458-463.

67. Wijeratne T, Sales C. Understanding Why Post-Stroke Depression May Be the Norm Rather Than the Exception: the Anatomical and Neuroinflammatory Correlates of Post-Stroke Depression. J Clin Med. 2021;10(8):1674. doi:10.3390/jcm10081674

68. Panagi L, Poole L, Hackett RA, Steptoe A. Happiness and Inflammatory Responses to Acute Stress in People With Type 2 Diabetes. Ann Behav Med. 2019;53(4):309-320. doi:10.1093/abm/kay039

69. Spalletta G, Cravello L, Imperiale F, et al. Neuropsychiatric Symptoms and Interleukin-6 Serum Levels in Acute Stroke. J Neuropsychiatry Clin Neurosci. 2013;25(4):255-263. doi:10.1176/ appi.neuropsych.12120399

70. Su J, Chou S, Tsai C, Hung T. Cytokine changes in the pathophysiology of poststroke depression. Gen Hosp Psychiatry. 2012;34 (1):35-39. doi:10.1016/j.genhosppsych.2011.09.020

71. Kolb B, Muhammad A. Harnessing the power of neuroplasticity for intervention. Front Hum Neurosci. 2014;8.

72. Papadakakis A, Sidiropoulou K, Panagis G. Music exposure attenuates anxiety- and depression-like behaviors and increases hippocampal spine density in male rats. Behav Brain Res. 2019;372.

73. Alain C, Moussard A, Singer J, Lee Y, Bidelman G, Moreno S. Music and Visual Art Training Modulate Brain Activity in Older Adults. Front Neurosci. 2019;13.

74. Stegemoller E. Exploring a Neuroplasticity Model of Music Therapy. $J$ Music Ther. 2014;51(3):211-227. doi:10.1093/jmt/thu023

75. Maher CA, Toohey M, Ferguson M. Physical activity predicts quality of life and happiness in children and adolescents with cerebral palsy. Disabil Rehabil. 2016;38(9):865-869. doi:10.3109/09638288.2015.1066450

76. Wang F, Orpana HM, Morrison H, de Groh M, Dai S, Luo W. Long-term association between leisure-time physical activity and changes in happiness: analysis of the Prospective National Population Health Survey. Am J Epidemiol. 2012;176(12):1095-1100. doi:10.1093/aje/kws199

77. Matheson GO. Changing level of physical activity and changing degree of happiness. Clin J Sport Med. 2014;24(2):162-163. doi:10.1097/JSM.0000000000000092

78. Chen YC, Chen C, Martínez RM, Etnier JL, Cheng Y. Habitual physical activity mediates the acute exercise-induced modulation of anxiety-related amygdala functional connectivity. Sci Rep. 2019;9 (1):19787. doi:10.1038/s41598-019-56226-z

79. Hachinski V, Avan A, Gilliland J, Oveisgharan S. A new definition of brain health. Lancet Neurol. 2021;20(5):335-336. doi:10.1016/ S1474-4422(21)00102-2

80. Grau-Olivares M, Arboix A. Mild cognitive impairment in stroke patients with ischemic cerebral small-vessel disease: a forerunner of vascular dementia? Expert Rev Neurother. 2009;9(8):1201-1217. doi:10.1586/ern.09.73 


\section{Publish your work in this journal}

Therapeutics and Clinical Risk Management is an international, peerreviewed journal of clinical therapeutics and risk management, focusing on concise rapid reporting of clinical studies in all therapeutic areas, outcomes, safety, and programs for the effective, safe, and sustained use of medicines. This journal is indexed on PubMed Central, CAS,
EMBase, Scopus and the Elsevier Bibliographic databases. The manuscript management system is completely online and includes a very quick and fair peer-review system, which is all easy to use. Visit http://www.dovepress.com/testimonials.php to read real quotes from published authors.

Submit your manuscript here: https://www.dovepress.com/therapeutics-and-clinical-risk-management-journal 